\title{
Regional Society as a Subject of Social Development
}

\author{
Igor Alexandrovich Guskov
}

Southern Federal University, Rostov-on-Don, Russian Federation

\section{Alexandr Vasilyevich Popov}

Southern Federal University, Rostov-on-Don, Russian Federation

\section{Oxana Yuryevna Posukhova}

Southern Federal University, Rostov-on-Don, Russian Federation

\section{Yury Yurievich Volkov}

Southern Federal University, Rostov-on-Don, Russian Federation

Pushkinskaya Street 160, Rostov-on-Don, Russia, 344006

Email: infoippk@sfedu.ru

Doi:10.5901/mjss.2015.v6n3s3p223

\begin{abstract}
Until now, the Russian centre and regions have not found a sustainable balance in the distribution of power, although after the collapse of the USSR and the formation of the Russian Federation there has been more than twenty years. The reasons appear, at first, to be the asymmetry of the Federation and the Constitution, founded on the concepts accepted in 1993, and, secondly, on a variety of economic, social, cultural, ethnic and other differences in the regions. This indicates that the mechanisms of relationships rest on the distribution of power, on the one hand, and on the other on that the regions in its current state have not reached subjectivity, domestic economic and social independence, which is indirectly witnessed by rising debt of the regions. Debt is only a symptom of the fact that the regions either have not learned to manage efficiently the available financial resources, or regions are oriented to subsidized development model. Attempts to shift the responsibility to the centre, to distortions in the budget policy only partly explain the situation. Local societies - regions, are selected on the basis of the administrative division of the state, and, in legal terms, are the subjects of the Russian Federation and the actual place of forming the foundations of social and economic stability, cultural standards and traditions of self-regulation. They are a source of self-organizing interaction of real social communities. The conditions for the development of the real existing community are based on self-organization. There is a single point of management of the economy, politics, social, military and other spheres of government in the face of the region, its legislative, judicial and military power. This advantageously distinguishes regional socio-cultural space based on administrative - state division of larger territorial associations, and include a number of areas and edges, and autonomous republics. The article notes that the Russian regions do not act as equal and interested partners of the state in addressing regional development. The author not only raises the issue of updating the subjectivity of the region, but also proposes ways and options to strengthen the subjectivity of regional society.
\end{abstract}

Keywords: region, regional development, management, teamwork, subject, subjectivity, Large territorial society.

\section{Introduction}

Background research is determined by the fact that the systemic crisis of the Russian society dictates the need to find new ways to manage the regions and territories subject to a large extent to a variety of dynamic changes, including new processes related to regionalization. The specifics of the moment requires effective social control and regulation of all the elements of the complex in its internal structure of the social organism, going through a stage of qualitative modifications.

Russian federalism model is developed under the influence of the crisis factors that coordinate system in which any attempt to "take as much sovereignty as you want to" turn around not only inter-regional tension, but also into conflicts with the centre. That is why the Russian federalism emphasis on centralization, while decentralization is seen as a carefully controlled, not subject to sudden changes and changes in the process. In this regard, we can say that multi- 
factor of regional development is determined by the status of the region in the current system of relations between the centre and the regions, the real socio-economic, socio-demographic, cultural (educational) potential of the region, regional traditions of society and the image, the image of the region in the social and cultural space .

Significant status of "superiority" leading regions is based on the fact that in the context of peculiarities of the Russian economic development to the fore of the natural rent and simultaneously operating factors of post industrialization. As a part of Russian society, classic workers make up 25\%. Overlay trends archaic (resource-based economy) and innovation of post-industrialism create fanciful configurations in which traced significant differences between the regions, not only for the objective socio-economic indicators, but also by what we call the level of subjectivity in the region.

A good example is the Kaluga region, which creates a powerful industrial cluster. In many respects, it is determined by not favourable geographical location, logistics capabilities, but by also quite deliberate and consistent investment policy of local leaders.

A significant factor in our opinion, is that the Russian regions, despite the political and legal formation, transfer a number of powers and the implementation of the principle of subsidiarity, but do not act as equal partners and interested States in addressing regional development. Important recent trends include the increasing importance of investment attractiveness of the region. In this area, the Rostov region done a lot. This region in general over the past 5 years, attracted more than 130 different investment projects that provide 70,000 jobs and a significant increase in the regional budget.

However, it can be emphasized that the effect of the so-called objective factors is not cancelled, it is obvious that in conditions of increasing natural disasters and unresolved spatial factor, the distance from the main centres of communication. In this connection, attention is drawn to the fact that the performance of subjectivity are measured not only the quality of the regional elites, but also a significant influence becomes state regional society, as a combination of various social, socio-professional and cultural groups in the regional space. In other words, the current time is marked by regions' search for subjectivity, abilities, on the one hand, to dispose the available social resources development, on the other - to formulate queries, articulate interests at the level of interaction with the centre at the level of implementation of joint projects for social development.

\section{Literature Review}

The first group is represented by an extensive scientific research literature on governance in general and social management, in particular. Among the scientists who develop these problems, it is necessary to allocate the works by Ansoff I. (Ansoff, 2007), A. Gouldner (Gouldner, 1954), P. Drucker (Drucker, 1999), I. Prigogine (Prigogine, 1984), A. Prigogine (Prigogine, 1995), Toschenko and many others.

The second group of problems - general policy management problems - is linked to the "market" paradigm of politics and political management in a competitive environment. Known work of representatives of the school of "public choice" are as follows: D. Buchanan (Buchanan, 1999), Veblen (Veblen, 1899), and (Sunde, 2006), who set out the idea of what is a political market, and attempt to relate conceptual constructing a political practice, especially with the experience of political development of democracy. Serious conceptual framework is laid down in the framework of neoinstitutional analysis, which became the subject of research institutions that form the living tissue, and the content of market relations including in the regional economy (North, 1990). Engineering problems are considered by P. V. Zayats (Zayats, 2013), an account of cultural differences in the management systems referred to in the works by Wieviorka M. (Wieviorka, 2010).

The third group consists of works devoted to the subjects of the control for the regions (Volkov, 2013) regional capacities (Posukhova, 2014), regional development (Tabellini, 2005), innovative development (Gafurof, 2014), and problems of regionalization (Taylor, 2013). But at the same time still the issues related to subjectivity regional society have not been studied.

Theoretical and methodological basis of the study are the works by the founders of classical and modern trends: the philosophical, historical, economic, sociological and political science paradigms and theories that identify the essence of the process of social change, works by domestic and foreign scholars in the field of complex systems theory, management, decision-making system and program-target approaches from other disciplines, containing analysis and theoretical conclusions on regional management and management of large territorial society, as well as municipal management and organization of local government.

A prerequisite for the development of the methodological foundations of modern sociological research problems in managing large territorial societies is the recognition of social and political process as an organizing principle in all 
spheres of social activity. It is a process of objective historical choice and changes in the management of the company, in its structures and institutions as a set of procedures that determine the basic direction - the vector of development.

Specific research tasks, which are the subject of the dissertation, require the use of complex scientific and special methods, the use of which is capable of providing paradigmatic vision of regional problems in the conditions of reforming the Russian state. Along with the systematic approach that provides a holistic view of the functional unity of the individual elements of a large territorial society, applied classical methods of analysis and synthesis methodology of knowledge of general and special, primary and secondary, historical and logical dialectic contradictory development of complex phenomena. The authors used a particular concept, attributive and functional approach to the study; considered important features of synergetic interpretation of the processes of development of complex dynamic systems, the results of the synthesis of the historical, political and empirical surveys, materials expertise and analytical reports all-Russian sociological research.

\section{Results}

Upon closer inspection, it turns out that the parameters of regional society, indicators of physical, social, health, social mobility, and existing economic and cultural practices can seriously affect the economic growth and the level of sociopolitical stability. Regional society is a complex regional system. It puts pressure risk factors and, at the same time, we can talk about the possibility of management of society in terms of social urbanizing environment.

A regional society is not the only an actor for which the regional space is both economic and social conditions of existence required to define the boundaries and sphere of influence on the processes occurring in the region. Thus, at this stage of regional development is a trend towards consolidation of regional society, suggesting that the process of transformation, even if slow and ambiguous, the local population in a certain community or collectivity.

The regional society and regional elites can form various management models in between that often proclaimed refutes to the idea that the control system is almost authoritarian. It is obvious that authoritarianism in decision-making power at the regional level due to a lack of socio-economic and social activity in the region.

In this respect, of course, their role belongs to the existing system of vertically integrated power of the Institute of appointment and the desire to prevent the centre and neutralize potential centrifugal tendencies in regional life. On the other hand, it must be noted that the regional society is characterized by uneven social activity.

Regional management is found in a situation in which there has been increasing social uncertainty and perceptions of helplessness regional power, while the development objectives of the region, determined by the ability to respond adequately to the various regional, in-country and global challenges. Regional society, despite the trend of consolidation in the ways of understanding the social development of the region and the vision, cannot get a unique name for the mature subject of social development.

Due to social immobility, there arises positive sense of attachment to their native areas, immediate environment, but at the same time, there is a provincialism and regional society, the closure of their own problems while maintaining high confidence in the social and state institutions.

While agreeing that the current risks in many ways can be a catalyst for regional solidarity of society, we cannot ignore the fact that the level of impact of risks and their consequences can lead to slower development of the region, and to the actual destruction of the regional society. In these circumstances, the only representative of regional society, ruling on behalf of the society and for the society, begins to speak of regional management system. Thus, we can say that subjectless or incomplete subjectivity regional society puts real practical problem of increasing the level of independence and responsibility, and the transition from the object state to state and within the partnership model and regional society, and at the level of inter-regional relations and relations centre and the regions.

In an increasingly scarce financial resources from the state to maintain the subsidy model of the approach to the problem of subjectivity from the perspective of leadership and management is effective.

Criteria of subjectivity of regional society advocates, firstly, towards the region as a habitat or development or social comfort environment. Secondly, the level of responsibility of the population, that is, its own assessment of independence in solving regional problem. Third, it is related to the regional and federal authorities.

At first glance, we can talk about the imbalance of these indicators, since, according to the positions of the Russians, they are characterized by a "charge" of the Russian bureaucracy in preserving and constantly increasing their wealth and influence, regardless of the standard of living of the population (Institute of sociology RAS, 2005).

One can also say that the regional society in Russia if to determine the level of subjectivity, is although composed as a community interested in the development of the region and understanding of the region as referred to in the social order, manifested a high enough level of conflict of interest regarding what may be the goal of regional development and 
what are the ways of development. In this sense, the regional authorities still cannot rely on the formation of intra-regional projects.

At least the desired ratio of regional society to regional problems is not supported by mechanisms, tools for their implementation. In particular, it is necessary, in fact within the meaning of the main condition, to mobilize quickly regional society for support and security and, to some extent, to understand the complexities of the implementation of regional problems (Posukhova, 2014). One gets the impression that the regional authorities and the regional society operate in parallel. Even if it is an obvious desire to increase regional management of social and investment potential, the image of the region shall be improved, such a positive attitude can run into a quiet resistance from regional society: either we did not affect anything, or it refers only to the authorities, the fulfilment of its power and influence and conservation own places. Even such a simple argument as the need for activity at the local level, the solution of local problems hampered by the narrow horizon of understanding and planning of the population without causing significant interaction at the household level.

Regional society is a representation of the interests of different sectors of the population. At the same time, we can say that space is expressed in the regional community of interests related to the satisfaction of the basic needs of the regional representatives of society: in the comfort, security, and identity. Perhaps scepticism about regional society in the Russian society is due to the fact that the region is still perceived as an abstract economic-economic space is not filled with the living dynamics of human feelings and beliefs.

Despite some very interesting regional initiatives, still the problem of subjectivity evaluation system of regional development cannot be satisfactorily solved within the framework of organizational planning approach. Important social consequences is the use of diagnosing the state of regional society, what sociological and cultural conditions, rules and regulations affect, but not least how, what meanings and values are attributed to regional population.

Social roles and responsibilities of regional society as a collective subject of social development, are extremely important, because the regional space ceases to be a physical, real, that it is the embodiment of the struggle and cooperation of various social forces that seek not only to their own interests, but also to possession of power, cultural and symbolic information resources. At the same time, the state of subjectivity regional society is a generalized indicator of the region's population to social transformations (Gorshkov, 2011).

Noting that there are significant determinants of the social development of the region, we assume that the regional society is characterized by increased social tone (optimistic), if the dominant perspective, an open mind, if the regional life is not associated with backwater, peripherals lag. Assessing the status of the Russian regions, there is reason to believe that their development is going on, but very slowly and ambiguously. The increase in the separation of the capital metropolis captures the real problem: the Russian regions feel their disadvantaged social benefits.

Regional society has a different degree of cohesion: societies with the settled population outside the migration routes, can be called settled areas, while there are migratory habits of raw space regions where cultural tradition is revealed not so significant, but there is a wide corridor of opportunities to meet the social benefits. These dispositions reflect the relative immaturity and inconsistency of social development, because it is a fact that the best result can be achieved if the regional society focused on finding their own niche in the socio-economic and socio-political space.

Landmark of the ethnographic tourism or new raw Klondikes remarkable that generates pulses of confidence, but can give rise to a sharp decline in social attitudes and discouragement in society, if expectations are not met. In addition, it should be remembered that the Russian regions are diverse not only in history and tradition, but also occupy an important place of education and professional qualification potential tradition of social participation. In this sense, differences between the Urals and the North Caucasus region are evident.

Regional society in varying degrees, showed the beginnings of subjectivity in the 90 -ies of XX century. It is important to understand that in the context of weak states in the region objectively took the decision to shipping problems, often beyond their competence. This has led to an increase in the role of regional elites and, to some extent, to the regional opposition, but the main result is that there actualization regional subjectivity, awareness of inhabitants of the region and the specific conditions under which they live, and certain common interests specific to all social groups in the regional space.

Image of the state in this period was controversial and federalism was presented with regional accent, as skewed in favour of the rights and responsibilities of the regions. But as the effectiveness of regional bureaucracy is estimated low enough and is often based on regional populism, we can say that the subsequent era recentralization accents. It is significant that the centre of the efforts implemented to streamline the social, political and legal space welcomed people in the regions for regional society understanding unitarity compares favourably with the regional diversity in the degree of accessibility to social resources and to ensure that the development of regions with few exceptions was not self-sufficient.

In the context of the transfer of the social sphere within the competence of regional governance, it is important to 
understand that the regional government cannot solve these problems alone is attracting resources of regional society. We are not talking about a resource of patience or conformity. Social development of regions becomes steady, if you start from the balance of regional and national interest.

It is important to emphasize that, despite the critical attitude towards the regional elites or to the centre, representatives of the regional society least likely to negatively evaluate and often own state. The fact that faced with the inertia of regional life, the narrowness of regional cooperation often claim respondents: they indicate that the level of mutual trust and cooperation narrowed down the scope of the family or close circle (Gorshkov, 2011). Such estimates of the reaction quite fit into the state of disintegration of society. Therefore, the most observed greater confidence to the President and completely indifferent attitude towards regional governance structures.

In varying degrees, the social development of the Russian regions unevenly. However, you can allocate enough solid opportunities to better utilize the potential of regions for sustainable development dynamic. It is called traditional fuel and energy potential, but attention is drawn to the low assessment of the impact of human potential regional society. Meanwhile, the resource becomes significant as health, because the costs of medical care, the prevalence of diseases, sanitary-epidemiological situation in the region to work together to create social conditions or jerk or aggravate the situation in the social sphere. In addition, the level of aging, alcohol abuse or drug addiction has a direct effect on the investment attractiveness of the region, making the region an aging population or degrading, contender for a place on the periphery of social development.

Changes in the geopolitical situation, the transition to high-performance economy make it impossible to claim that if the Russian Federation on the territory of the country self-sufficient and mineral resources. The tremendous value of interregional differences due to the fact that the scheme is reproduced by "rich - poor" regions. $2 / 3$ of the Russian Federation subjects have proportion of the population with incomes below the subsistence level above the average for Russia. But regional society can, if not radically, then significantly change this situation through new technologies redefining the movement and intensity of communication (Zemnukhova, 2013).

It may be noted that the development of Russian regions in the framework of the national development strategy does not eliminate the variability of approaches to regional problems. Moreover, the implementation of federal target programs, inter-regional and regional projects shows that the independence and competence of the regional society depends on the way in which development priorities given primacy. Expectations of economic growth, especially due to the arrival of foreign investors, often drives to the situation unrealistic expectations and a winning attitude seems those regional communities, where at least at the local level found mechanisms of self-support and self-development (Novgorod, Pskov, Yaroslavl, Nizhny Novgorod, and Rostov region).

The duality and ambiguity practices of globalization reinforces the need not only in determining the national-cultural civilizational identity (Gorshkov, 2011), but also makes an important component of regional identity, awareness of belonging and involvement in the life of the region as a social and cultural space.

Growth in employment, self-employment, expansion of amateur legal practitioner commits to the fact that in the conditions of occurrence of large corporations or rigidity of public policy recognizes the involvement of citizens in the solution of current regional affairs, formed a strong opinion about the benefits of social and political participation. Based on the fact that none of the regional society as a collective entity, should not have precedence over the other, it can be said that the sharp decline in political activity of citizens may well be offset by interest in social development issues.

It would be wrong to say that indifference to regional life is a total character: from $12 \%$ to $14 \%$ of Russians persistently show interest in regional issues. On the one hand, it seems insignificant index, on the other - powerful enough to evict the deadlock life in regional society.

The allegation that the regional society is passive, could become a kind of general sociological constants. But as a rule, in the life of a regional society deviates from the stated position, as the emphasis in social development can be arranged differently. The key problem of regional society is the lack of consolidation and mobilization and non-inclusion of resources possessed by the region in addition to raw materials. What is seen as a way out of this situation and what should be done to ensure that the regional society effectively involved in social development?

In our opinion, it is necessary to increase the social and political activity of specific groups, and the whole region. Without disputing the desirability of democratic and accountable forms of regional governance, we should talk about what is required, and a sharp increase in the educational potential, social Resource regional society in order to be met by a system of regional governance requirements were, at least, correspond to the state of society. At the level of regional management needed skills that can be co-opted from the regional society, provided that the regional space formed sufficiently dense layer of professional managers.

Contrary to popular opinion, that the population expects from the regional administration only positive distribution of social policy has been an increase of the criteria of professionalism and competence of officials, their diligence and 
efficiency, initiative, good organizational skills (Institute of sociology RAS, 2005). Thus, despite the constant social independence, the population realizes that the electoral mechanisms are not sufficient to guarantee to improve the quality of regional governance and the effectiveness of regional management is defined by openness, receptivity and innovativeness of the regional society.

As noted above, the population's attitude to the role of regional society is clearly biased, although the majority of Russians recognize that activity is at the regional level hardly possible to ensure the sustainable development of the regions. Not enough, apparently, to bring society in a positive state-mobilization, confidence in the fact that the initiative in the region can solve most important problems without the participation of the centre or in conjunction with the centre. It is a departure from the position laid indifference seems to be the potential consolidation of regional society. And it is as follows.

As regional development is important in the formation of the complex and contradictory regional context, a new way of regional "we" that would successfully be inserted into the new system of relations, develops new social meanings and values (Gorshkov, 2011). Perceptions of the region as a dependent and passive community responds only formula dependent control. As a negative consequence of what is happening can be considered the fact that, in discussing the problems of regional life, complaining about the arbitrariness of power and selfishness, regional subjectivity is perceived as a virtually unachievable ideal.

So, bringing regional society in subjective state requires, firstly, to identify and to create new opportunities for social growth of the population; secondly, to formulate universally valid priorities for regional development; Third, it requires to create an atmosphere of mutual trust along with the hope that with the increase of social activity of the population can occur qualitative change crisis.

Sociological analysis shows that changes in self-perception of people in Russian society over the past two decades is truly colossal. And they manifest themselves primarily in the significant reduction of those who feel social outsiders see themselves as representatives of the middle strata (Gorshkov, 2011). This certainly affects the stability in Russian society. But the consolidation of social complacency at the individual level, unfortunately, is not modelled on the state of activity at the level of regional society.

Feeling quite satisfied socially, people are often in the position of regional society regards as unsatisfactory. This can be explained by what is called microscopy of the individualization of social relations and life strategies, narrowing the scope of security and social belonging. Assessing the situation as a crisis in the country (67\%) (Gorshkov, 2011), we must not forget that Russia has regional heterogeneity and, along with the negative depressive tendencies in the regional map of the country there are regional societies, successfully meeting the current socio-economic context.

Regional society objectively becomes the subject of social development, as is the subject of preservation of the state and, at the same time, address the issues of regional management, heterogeneous in nature, economically, socially and culturally. The inefficiency of the economic and political empowerment allows hyper-centralism regional development. But the real shift from administrative to social practices is possible if regional society involved in the processes of regional development through the use of their own forces at different levels.

Economic considerations may play some role, but the main reason is a request to improve the quality of life in regional society. The most popular qualities can be considered an interest in regional interests, diligence, initiative, respect for people, the pursuit of long-term design.

While agreeing with the statement that the regional society is not identical to the population that takes time and transform to there working social community, this period cannot be attributed to the distant future. Moreover, the assessment of regional societies suggest that improvements in the economic and social spheres connected by the extent to which people feel that they belong to the regional community, to ensure that, in assessing their own different sociostatus positions and social complacency, have a good opportunity to realize himself as a representative of regional society, build on regional identity as the current formula of social cooperation.

Lack of consolidating intentions and a tendency to social isolation reproduce decried subjectless. The relevance of the formation of subjectivity regional society cannot be given no matter whom. This process is indispensable influence of regional governance, as well as institutions engaged in regional representation.

The fact that, in such a way, the regional society tends to increase, gradually, albeit slowly develops as a collective subject of social development, sees prospects of transition management of administrative regions in central participant and socio-programmed. Amplified target function control system aimed to ensure that the regional authorities had acted in coordination with the centre representatives and interested in the social development of the regions.

Until now, however, there remains a clear negative impact of regional disparities. Redistributive policies budgetary resources mitigates inequalities, but it is mainly to "patch" the hole and is aimed at promoting social modernization. Formation of regional society as a subject of social development entails important implications as that, firstly, the region 
ceases to be a zone of borrowing resources, recipient, devoid of desire to build their own funds. Second, resistance is acquired by the fact that the generated optimal coordination mechanisms of the regional authorities and the various regional groups of society. Third, with respect to regional society should also be noted that in Russian society has undergone fundamental changes related to the fact that sharply reduced the number of paternalistic attitudes and social groups' dependency.

Although obvious is the presence of persons whose main income wages, regional society has sufficient intellectual, social and human potential in order to, in spite of the gaps between the quality of life and resource potential, to set ambitious but achievable targets for sustainable social development and to define in general increase in consolidation of the Russian space as an adequate response to the risks of destabilizing economic and social separation of the country.

\section{References}

Ansoff, I. (2007). Strategic Management Classic Edition. Palgrave Macmillan; First Edition.

Buchanan, J. (1999). Logical Formulations of Constitutional Liberty, Vol. 1, Indianapolis.

Drucker, P. (1999). Management challenges for the 21st century. Oxford: Butterworth Heinemann.

Gafurov, I. R., Platonova, O. U., \& Pratchenko, O. V. (2014). New state economic policy - cluster policy cluster policy as the factor of innovative development of Europe. (P. 107-111). Mediterranean Journal of Social Sciences, 5(12).

Gorshkov, M. K. (2011). Russian society as it is. (P. 259 - 306). M.: Institute of sociology RAS.

Gorshkov, M.K. (Ed). (2007). Regional sociology in Russia. M.: Exlibris-Press. P. 30 - 96

Gorshkov, M.K. (Ed). (2012). The Russia under reforms. (P. 106.). Vol. 11. M.

Gouldner, A. (1954) Patterns of Industrial Bureaucracy. Glencoe, Illinois: The Free Press.

Institute of sociology RAS. (2005). Bureaucracy and power in the new Russia: position of the population and assessments by the experts. (p. 34, 38, 50). M.: Institute of sociology RAS.

North, D. (1990). Institutions, Institutional Change and Economic Performance. Cambridge: Cambridge University Press.

Posukhova O.Y., Zayats P.V. (2014). Social engineering as a mechanism of optimization of human resources management in rostov region. (p. 424-428) Middle East Journal of Scientific Research. Vol. 19. No. 3.

Prigogine, I.; Stengers, I. (1984). Order out of Chaos: Man's new dialogue with nature. Flamingo.

Prigozhin A. I. (1995). Modern sociology of organizations. M.

Sunde, U. (2006). Wirtschaftliche Entwicklung und Demokratie - ist Demokratie ein Wohlstandsmotor ode rein Wohlstandsprodukt? Perspektiven der Wirtschaftspolitik, 7(4):471-99.

Tabellini, G. (2005). Culture and Institutions: economic development in the regions of Europe. IGIER, Università Bocconi, Working Paper № 292.

Taylor, P.J., Derudder, B., Hoyler, M., \& Ni, P. (2013). New regional geographies of the world as practised by leading advanced producer service firms in 2010. (pp. 497-511). Transactions of the Institute of British Geographers, 38 (3),

Veblen, T. The Theory of the Leisure Class. Retrieved from: http://socserv2.mcmaster.ca/ econ/ugcm/3ll3/veblen/leisure/chap01.txt

Volkov, Y. (2013). Creative Tendencies in Regional Elites' Activity. World Applied Sciences Journal 28 (2): 180-184. Retrieved from: http://www.idosi.org/wasj/wasj28(2)13/6.pdf http://www.idosi.org/wasj/wasj28\%282\%292013.htm

Wieviorka, M. (2010). Sociology in times of crisis. Facing an Unequal World: Challenges for a Global Sociology. Vol. 1: Latin America and Africa. Taiwan: Academia Sinica.

Zayats, P.V.\& Posukhova, O.Y. (2013). Engineering of political party systems: experience of methodological designing in sociohumanitarian knowledge. (p. 1628-1632). World Applied Sciences Journal. Vol. 26. No. 12.

Zemnukhova, L. V. (2013). Information technology as a professional environment. (P. 57). Journal of Sociology. No. 4. 
ISSN 2039-2117 (online) ISSN 2039-9340 (print)
Mediterranean Journal of Social Sciences MCSER Publishing, Rome-Italy
Vol 6 No $3 \mathrm{~S} 3$ May 2015 